\title{
O REFÚGIO DO TRAUMA. NOTAS ETNOGRÁFICAS SOBRE TRAUMA, RACISMO E TEMPORALIDADES DO SOFRIMENTO EM UM SERVIÇO DE SAÚDE MENTAL PARA REFUGIADOS
}

The trauma refuge. Ethnographic notes about trauma, racism and suffering temporalities in a mental health service for refugees

Alexandre Branco Pereira*

\begin{abstract}
Resumo. Este artigo apresenta reflexões etnográficas realizadas a partir de trabalho de campo em um serviço de assistência em saúde mental para refugiados na cidade de São Paulo, e em outros contextos. Aponto para como a categoria trauma, pressupondo um sofrimento passado, é acionada pelo serviço de saúde mental, mas não pelos sujeitos atendidos, que recorrem a temporalidades presentes e futuras de sofrimento na requisição de auxílio junto a esses serviços, demonstrando como as abordagens são reformuladas ou não face a apresentação dessas temporalidades de sofrimento distintas.
\end{abstract}

Palavras-chave: refugiados; saúde mental; trauma; racismo; antropologia.

Abstract. This paper presents ethnographic reflections from my fieldwork in a mental health assistance program for refugees in the city of São Paulo, and in other contexts. I point to how the notion of trauma, which entails a kind of suffering that takes place in a past time, is mobilized by the mental health service, but not by the subjects assisted by them, that mobilize present and future temporalities when requesting this kind of aid, demonstrating how these approaches and interventions are reformulated or not when facing these distinct temporalities of suffering.

Keywords: refugees; mental health; trauma; racism; anthropology.

Mestrando no programa de Pós-Graduação em Antropologia Social da UFSCar (PPGAS/UFSCar), membro do Laboratório de Estudos Migratórios (LEM/UFSCar) e bolsista CAPES-DS. São Paulo, SP, Brasil. 


\section{Introdução}

Este artigo intenciona apresentar algumas notas acerca de meu trabalho etnográfico junto a refugiados ${ }^{1}$ atendidos por serviços de saúde mental na cidade de São Paulo e, paralela e simultaneamente, também acerca dos próprios serviços, seus agentes e agenciamentos, uma vez que a apreensão de uma perspectiva a partir do ponto de vista tanto dos usuários dos serviços, quanto dos próprios serviços em si se torna importante para a composição do quadro que se pretende montar. É importante ressaltar o ineditismo da análise antropológica sobre serviços de saúde mental para refugiados no Brasil, e a ausência de trabalhos etnográficos que perscrutem as lógicas engendradas por esses mecanismos, tidos aqui como mecanismos de recepção, adaptação e integração desses refugiados no Brasil, além de ser igualmente inédito o estudo antropológico sobre a perspectiva para além do ponto de vista institucional, ou seja, a partir da experiência subjetiva do refúgio e de seus sujeitos.

Nesse sentido, a análise da questão no Brasil se deu, até o presente momento, a partir de abordagens desde a psicologia (Debiaggi, Paiva, 2004; Dantas, 2012; Knobloch, 2015), a psiquiatria (Santana, Lotufo-Neto, 2004; Medeiros et alii, 2014), a psicanálise (Rosa et alii, 2009; Rosa, 2012) e a saúde coletiva (Knobloch, 2015; Galina et alii, 2017), cujas preocupações, entre outras, estão em realizar uma espécie de mapeamento epidemiológico da incidência de transtornos mentais entre imigrantes e refugiados, e na instituição de um campo de conhecimento e de práticas clínicas sobre abordagens interculturais dos problemas mentais de refugiados e imigrantes, o que não é o interesse desse trabalho. As etnografias recentes sobre o refúgio no Brasil, apesar de contribuírem enormemente para o debate sobre essa questão ainda subexplorada, não fornecem análise sobre os serviços de saúde mental para refugiados, nem abordam antropologicamente a experiência dos refugiados atendidos por esses serviços (Perin, 2014; Navia, 2014; Hamid, 2012; Mejía, 2010; Lopez, 2015). Perin (2014), inclusive, chega a mencionar en passant que, em sua pesquisa realizada na Cáritas Arquidiocesana de São Paulo, não Ihe foi possível acompanhar o serviço de saúde mental para refugiados por este estar em processo de reformulação quando de sua presença em campo².

\footnotetext{
Esse trabalho irá considerar as categorias "refugiado" e "solicitante de refúgio" tal qual são usadas pelos informantes em campo, de maneira mais ampla do que a conformação jurídico-legal dos termos. Por isso, por vezes haitianos serão incorporados na categoria de refugiados, ainda que sua situação tenha um estatuto jurídico diferente daquele dos demais refugiados. Além disso, daqui em diante será usado o gênero masculino genérico para se referir aos refugiados, especificando quando forem mulheres. Tal escolha foi feita pelo fato de a maioria absoluta dos sujeitos refugiados encontrados em campo serem homens.

2 Entrevistas realizadas com psiquiatras que trabalharam em tal serviço dão conta de que a reestruturação completa do mesmo, que tem por volta de 20 anos de existência, se dá com alguma frequência em função de o convênio com o ACNUR ter de ser renovado a cada seis meses.
} 
Internacionalmente, a produção etnográfica acerca do tema é mais extensa e antiga, configurando o que Malkki denomina de "proeminência das interpretações psicológicas do deslocamento", atingindo também cientistas sociais imbuídos na análise da questão (Malkki, 1995, p. 509-510). É possível destacar, entre vários outros, os trabalhos de Fassin (2001) e Fassin e Rechtman (2009), que abordam a transformação da categoria do trauma em um instrumento clínico e político destinado a aferir a veracidade do sofrimento dos solicitantes de asilo na França, além de um movimento desses sujeitos no sentido de aprenderem e se apropriarem das categorias de diagnóstico psiquiátrico; e Pussetti (2010; 2017) e Ferreira (2011; 2012), que apontam para os conflitos vividos pelos - e o emudecimento político dos - refugiados e imigrantes indocumentados atendidos por serviços psiquiátricos transculturais em países europeus, ainda que Pussetti (2017) já aponte também para uma apropriação das categorias nosológicas ${ }^{3}$ da psiquiatria por parte dos refugiados, coproduzindo o lugar do trauma.

Nesse sentido, o principal interesse desse artigo é realizar uma análise dos primeiros dados etnográficos, dialogando com a literatura nacional e internacional, levantados sobre esses serviços, cuja implementação é relativamente recente no Brasil ${ }^{4}$, e os sujeitos atendidos por eles. Tomando o instrumento etnográfico a partir da perspectiva de Peirano (2014), considerarei a etnografia como uma formulação teórico-etnográfica, ou uma postura metodológica que também consiste em uma postura teórica. Nesse sentido, produzir conhecimento sobre refugiados atendidos por serviços de saúde mental a partir do exercício da etnografia destina-se a uma produção teórica diferenciada dos campos de saberes psi, da saúde coletiva, da medicina, das relações internacionais e do direito internacional, justamente pelo diferencial do instrumento etnográfico. Por essa razão, essa pesquisa terá a preocupação de simetrizar (Latour, Callon, 1992; Latour, 1994) os discursos de psicólogos, psiquiatras, agentes estatais e supra-estatais, voluntários e refugiados - não desconsiderando, entretanto, que tais relações podem conter, e efetivamente contêm eventuais assimetrias de várias estirpes -, cuidando para evitar as narrativas sobre o "nativo desinformado", e tomando o refugiado como tão ou mais informado sobre sua condição quanto, teoricamente, o são os "especialistas" que compõem esse cenário (Kirsch, 2006). Dessa forma, a intenção é erigir um relato "não purificado" (Latour, 1994) que possibilite a audição dos relatos desses emissários sem voz (Malkki, 1996) tanto quanto dos relatos sobre eles - questionando, por vezes, a própria avocalidade desses sujeitos.

\footnotetext{
3 Nosologia é o ramo da medicina que estuda e classifica as patologias, sendo "categorias nosológicas" as categorias categorizantes do saber médico.

${ }^{4}$ Os serviços de saúde mental para refugiados mais antigos do Brasil completaram vinte anos em 2017.
} 


\section{O Projeto de Saúde Mental para refugiados: entrada e escolhas metodológicas}

Os dados aqui apresentados são fruto de incursões iniciais em campo realizadas entre maio e outubro de 2017. Tais incursões se deram em um serviço de saúde mental direcionado ao atendimento de refugiados oferecido por uma ONG na cidade de São Paulo, além de contatos realizados em outras esferas de atuação dessa rede de serviços (composta por um número cada vez maior de instituições), como em palestras, reuniões e eventos organizados por eles. Optei, a princípio, por não especificar nominalmente esses serviços, seus agentes - funcionários ou voluntários - e os refugiados atendidos por razões metodológicas, observando principalmente o estágio inicial da fase de levantamento de dados etnográficos e a possibilidade de fechar as portas do campo etnográfico em um momento pouco oportuno.

O serviço de saúde mental em que as primeiras incursões se deram funciona desde o início de 2016, sendo, portanto, o programa do tipo cuja implementação era a mais recente quando do início da pesquisa. Localizado na cidade de São Paulo, que concentra a maioria absoluta dos serviços desse tipo para refugiados, esse serviço é apoiado financeiramente pelo Alto Comissariado das Nações Unidas para Refugiados - ACNUR -, sendo o único projeto da ONG a receber esse tipo de aporte supra-estatal. Sua coordenadora, por exemplo, era a única funcionária remunerada da instituição, cuja equipe era composta por voluntários, em sua maioria. O Projeto de Saúde Mental (PSM, daqui em diante) tem por objetivo, expresso no site oficial da ONG, "contribuir para a integração social de refugiados e solicitantes de refúgio no país de acolhida por meio da redução dos traumas psicológicos e transtornos emocionais, levando em conta seu contexto cultural e de migração", e funciona em três frentes, como me foi explicado pela coordenadora: os atendimentos psicoterapêuticos individuais, os grupos terapêuticos - chamados de grupos de troca -, e as oficinas temáticas voltadas para a capacitação profissional, no caso dos adultos, e para a musicalização, no caso das crianças.

Desde a primeira entrevista, a coordenadora do PSM, psicóloga, me disse que o serviço "ainda era pouco frequentado". Os atendimentos individuais aconteciam raramente, e apenas quando solicitado por algum refugiado. Os grupos terapêuticos eram marcados para os dias em que aconteciam as aulas de português a fim de atrair mais participantes - inclusive pessoas que não tinham o estatuto de refugiado, nem poderiam solicitá-lo, mas que também compareciam às aulas de português, como cidadãos franceses e estadunidenses -, e a presença desses sujeitos nos grupos era rotativa, alternando muito entre uma semana e outra (quando o grupo não era desmarcado ou pela ausência de participantes, ou pela falta de disponibilidade por parte dos membros da 
equipe responsável por coordená-lo). Os encontros dos grupos terapêuticos se estendiam por oito semanas, com reuniões semanais, e um havia terminado recentemente quando da minha primeira visita, em maio. A coordenadora do PSM me disse, então, que outro grupo deveria começar nas próximas semanas, e perguntei se poderia acompanhá-lo. Ela respondeu afirmativamente, dizendo que, se eu estivesse disposto, eu poderia conduzi-lo como voluntário.

Inicialmente, tal proposição me deixou incomodado por teoricamente dificultar minha presença enquanto pesquisador naquele lugar. Conduzir o grupo como voluntário seria coproduzi-lo enquanto ator chave, profundamente comprometido com a forma e o conteúdo das discussões ali realizadas. Além disso, havia as questões éticas em consequência da teórica perda da neutralidade axiológica esperada em campo: eu não seria mais pesquisador, mas voluntário. Outras colegas que atualmente trabalham com refugiadas também tiveram sua incursão em campo através do trabalho voluntário, como em Almeida (2017, no prelo). Heath Cabot (2013) também realizou trabalho etnográfico enquanto voluntariava em uma ONG de recepção de refugiados na Grécia, relatando que tal posição "levantou questões éticas e metodológicas que eram frequentemente difíceis de navegar" (Cabot, 2013, p. 455, tradução minha). A autora pontua que seus encontros com os solicitantes de asilo eram profundamente mediados por seu próprio papel de voluntária e pelas assimetrias de poder intrínsecas a essa posição - no caso dela, por exemplo, envolveria a concessão ou não de ajuda legal e assistencial, e até do próprio estatuto de refugiado. Entretanto, ela ressalta que também estabeleceu contato intenso com muitos refugiados e solicitantes de asilo fora dos contextos de seu trabalho voluntário, o que a permitia explorar realidades mais amplas que solicitantes de refúgio enfrentam na Grécia. Por fim, a autora afirma que sua atuação como voluntária lhe permitiu estabelecer abordagens de empatia mútuas com os trabalhadores desses serviços, "reconhecendo as incertezas, ansiedades e outros desafios que caracterizam seu trabalho" (ibidem).

Assim, decidi não "purificar" a pesquisa e a minha abordagem metodológica, ainda mais de um campo que já havia apresentado problemas muito difíceis de transpor quando de minha entrada - muitos contatos não respondidos e respostas negativas às minhas tentativas de acompanhar o trabalho desses serviços, o que se repete até o presente momento. Aceitei a oferta de conduzir o grupo terapêutico por oito semanas como voluntário da ONG, preocupando-me em estabelecer relações com a equipe do PSM voluntários ou não -, com a equipe de voluntários da ONG de maneira mais ampla, e com os refugiados atendidos. Com muitos desses foi possível, inclusive, trocar contatos e manter comunicação através de redes sociais, combinando também visitas esporádicas fora do ambiente da ONG e mantendo conversas até o dia de hoje. Além disso, pude estabelecer contatos com outros serviços de 
saúde mental para refugiados localizados na cidade de São Paulo e com a Rede para Cuidados em Saúde de Imigrantes e Refugiados, composta por diversos serviços de saúde - majoritariamente serviços de saúde mental - destinados ao atendimento de imigrantes e refugiados.

Passarei agora a apresentar a dinâmica dos eventos acompanhados, procurando realizar uma reflexão sobre os agenciamentos possíveis - e frequentes - das categorias de raça e racismo entre refugiados, voluntários e trabalhadores dos serviços de saúde mental. Também tentarei argumentar que essas categorias, articuladas à categoria de trauma - muitas vezes tido como inerente à condição do refúgio -, parecem engendrar a coprodução de tipos de sujeito elegíveis à ajuda oferecida, além do próprio tipo de ajuda que se oferece ou que se requer. Por fim, procurarei apontar como serviços e refugiados parecem trabalhar com noções de diferentes temporalidades do sofrimento elegível como alvo de uma intervenção em saúde mental, o que dificulta, por vezes, o diálogo entre as partes.

\section{Os grupos terapêuticos: a busca pelo sofrimento passado}

Os grupos terapêuticos funcionam como grupos de verbalização (Branco Pereira, 2014), e se inserem em um contexto de multiplicação de "novas abordagens que vislumbrassem a dimensão psicossocial do sofrimento e que levassem em consideração a subjetividade humana e a inclusão social, por meio da cidadania e da autonomia" (Benevides et alii, 2010, p. 128), suscitado a partir da Lei Reforma Psiquiátrica (Lei 10.216/01). Esses grupos têm como suposto objetivo potencializar "as trocas dialógicas, o compartilhamento de experiências e a melhoria na adaptação ao modo de vida individual e coletivo" (ibidem). Os grupos terapêuticos da ONG pesquisada receberam o nome de grupos de troca. A escolha desse nome foi feita por um dos voluntários do PSM, francês com formação em psicologia e antropologia, que iniciou seu trabalho após minha primeira visita ao lugar. De acordo com a coordenadora do PSM, com quem continuei mantendo contato por redes sociais, ele conduziria junto a mim os trabalhos do grupo, uma vez que ela estaria ausente durante as primeiras reuniões.

Já de início, pude atestar algo que a coordenadora do PSM havia me adiantado: os grupos de troca não eram exatamente um sucesso de público. As reuniões, que deveriam ocorrer semanalmente, não aconteciam com essa regularidade - a maior parte das vezes, pela ausência de interessados. Nos dias marcados para ocorrerem as reuniões, eu e o outro voluntário do PSM passávamos pelas salas onde estavam sendo ministradas as aulas de português explicando o que era o grupo e convidando - em português, inglês e francês - os refugiados para irem à reunião que ocorreria após a aula. Também mandávamos mensagens de texto para pessoas que durante a semana haviam 
manifestado interesse em participar. Quem fazia o recolhimento desses contatos durante a semana era o voluntário do PSM, uma vez que eu só ia nos dias em que a reunião efetivamente ocorreria (às segundas-feiras). Das oito reuniões previstas, apenas duas ocorreram de fato. Nos outros dias, por sete vezes nenhum refugiado se interessou em comparecer, e houve um caso em que apenas um refugiado sírio estava presente. Nesse dia, ao invés de requisitar o atendimento psicológico, ele se ofereceu para dar uma aula de árabe para mim e para o outro voluntário do PSM, o que substituiu as atividades do grupo.

A coordenadora do PSM havia me dito, em nosso primeiro encontro, que sua percepção era de que a maioria dos refugiados sofre de "falta de assistência" no Brasil. Ela mencionou poucos casos em que o refugiado foi encaminhado para serviços de saúde mental ligados ao Sistema Único de Saúde com suspeita de Transtorno de Estresse Pós-Traumático - TEPT - ou de depressão grave, ainda que faça mais uma vez a ressalva de que não é possível falar em depressão ou trauma, pois a "falta de assistência" era vista como a causa dos problemas emocionais que poderiam ser lidos, através de um viés medicalizante, como um quadro depressivo ou traumático. No entanto, também pude ouvir dela que, apesar disso, sua hipótese universal previamente definida era a de que o refugiado que procurava o serviço terapêutico oferecido pela ONG tinha algum grau de trauma em decorrência das experiências - traumáticas - inerentes à experiência do deslocamento forçado. A própria comunicação veiculada no site da ONG deixa expressa essa inferência, como pontuado anteriormente.

Não se pode, entretanto, questionar diretamente os refugiados sobre esses traumas passados: é preciso que a iniciativa em abordar o assunto parta deles. Essa foi uma recomendação da coordenadora do PSM feita em nosso primeiro encontro, que afirmou que não se podia questionar a eles a forma como eles vieram parar no Brasil - e é interessante notar a equivalência entre perguntar sobre a forma como esses sujeitos vieram parar no Brasil e perguntar sobre o trauma. Por isso, durante as reuniões dos grupos, as perguntas feitas pela coordenadora e pelo voluntário do PSM eram sobre as dificuldades enfrentadas pelos participantes de maneira bem geral. As respostas orbitavam dois temas principais: a dificuldade com o aprendizado do português e a dificuldade em arranjar um emprego. Eles não traziam suas histórias de vida, seus sofrimentos passados - os traumas -, teóricas consequências advindas dos eventos motivadores do deslocamento forçado e conformadores da experiência de vítima do refugiado, além de serem o próprio substrato que justificaria a existência desse serviço. Eles apresentavam as histórias de sofrimentos presentes e sofrimentos futuros: a dificuldade em aprender o português, derivada de uma oferta vacilante de aulas gratuitas e em locais da cidade que fossem acessíveis; a decorrente facilidade em serem enganados por não conseguirem falar a língua; a dificuldade em conseguir um emprego, também 
consequência das dificuldades com a língua - vários chegaram a cobrar da ONG que encaminhasse os refugiados para entrevistas em que só estrangeiros participavam, pois os empregadores costumavam preferir os brasileiros "por conta da língua"; a dificuldade de se fazer amizade com brasileiros, também derivada da falta de familiaridade com a língua portuguesa e, no caso de haitianos e africanos, a dificuldade com o racismo, tema do próximo tópico.

A pressuposição do trauma como critério de elegibilidade (Fassin, 2001; Fassin, Rechtman, 2009; Cabot, 2013) para o fornecimento de auxílio psicoterapêutico se mostrava, sob a perspectiva oficial dos fornecedores de auxílio, como tentativa de apreensão dos sofrimentos passados - os eventos traumáticos que motivaram o deslocamento forçado. A experiência do PSM, entretanto, parece demonstrar que os refugiados não remontam ao passado quando questionados sobre suas dificuldades - e isso pode ser atestado inclusive nas falas dos agentes do serviço de saúde mental, que reconhecem língua e emprego como as principais dificuldades desses sujeitos, e passaram a direcionar os grupos terapêuticos para a discussão desses temas (fosse diferente, os grupos de troca seriam ainda menos frequentados?).

Entretanto, o que justifica institucionalmente a existência do serviço dessa ONG continua sendo a pressuposição de um trauma decorrente do deslocamento forçado, ainda que o próprio refugiado não corrobore esse enunciado. Entre as causas elencadas como explicação para a baixa frequência nos grupos terapêuticos é a de que esses sujeitos "dizem não ter traumas", como me afirmou a coordenadora do PSM, configurando uma espécie de "resistência" ao tratamento psicoterapêutico. Ainda que tenha sido dito que a recusa ao enquadramento por parte dos refugiados possa ser tida como uma espécie de "resistência", ela mesma fez a ressalva de que não é possível falar de resistência entre esses sujeitos justamente pelas "dificuldades enfrentadas por eles", inclusive em comparecer à terapia, individual ou em grupo, que ocorre na sede da ONG e exige, muitas vezes, que esses sujeitos se desloquem das periferias da cidade para comparecer ao atendimento psicoterapêutico. Entretanto, as mesmas dificuldades poderiam ser observadas no caso das aulas de português e do projeto de trabalho e renda, que, no entanto, eram muito mais assiduamente frequentados do que as reuniões do PSM. Ela citou, inclusive, o caso de uma mãe angolana que recebeu a recomendação de tratamento psicoterapêutico para sua filha e recusou, dizendo que sua filha "não tinha trauma"5. O trauma, portanto, seria algo que os serviços sabem que o refugiado tem, ainda que ele próprio não o saiba, pois crê em outra coisa não seria essa a maldição da tolerância apontada por Stengers (2011)?

\footnotetext{
5 Infelizmente, esse foi um caso que não pude presenciar. Trago aqui o relato tal qual me foi descrito pela coordenadora do PSM.
} 
Por fim, também parece ser possível apontar para a coprodução do ambiente psicoterapêutico e dos critérios de elegibilidade para adentrá-los, como também o fazem Cabot (2013), Zelaya (2016) e Pussetti (2017): o grupo de troca não trata do trauma passado pois não é o que o sujeito do refúgio traz para trocar. Talvez seja possível concordar com Zelaya (2016) sobre a existência de um "campo de interlocução em transformação", sugerindo a construção de novos sentidos para a experiência do refúgio, afastados da imagem do refugiado enquanto vítima (Zelaya, 2016, p. 419) - ou, ao menos, enquanto vítima de seu passado e de sua experiência de deslocamento forçado. Aponta-se agora para o questionamento da imagem do Brasil enquanto país natural e tradicionalmente acolhedor de imigrantes e refugiados (Hamid, 2012; Navia, 2014; Zelaya, 2016) por parte de alguns dos sujeitos do refúgio - e esse questionamento não acontece sem tensionar a relação entre agentes governamentais e não-governamentais e os refugiados, como tentarei demonstrar no próximo tópico.

\section{Refúgio branco e refúgio negro: a "descoberta" do sofrimento presente, e a projeção do sofrimento futuro}

Desde minha primeira visita à ONG, a questão racial me foi apresentada como algo pungente. A coordenadora do PSM me disse em nosso primeiro encontro que "os refugiados descobrem que são negros no Brasil", referindo-se à forma como o preconceito racial "revela" a esses sujeitos o "fato" de que eles são negros. Ela não se referia à percepção, por parte desses sujeitos, de uma característica fenotípica referente à cor de sua pele, ou de qualquer outra característica acionada para a descrição do "ser negro" no Brasil: não é que os refugiados nunca haviam notado que sua pele é escura, mas que, antes de chegar ao Brasil, esses refugiados "afirmam não ter pensado na questão racial" (Zelaya, 2016, p. 414).

Não é difícil encontrar reproduções dessa mesma frase, mesmo entre refugiados - seja em matérias jornalísticas, análises sociológicas, eventos de sensibilização e visibilização sobre a questão migratória e do refúgio e até análises etnográficas (ibidem). A questão racial permeou toda minha experiência inicial de inserção em campo: a coordenadora do PSM, por exemplo, disse que procura realizar uma "sensibilização dos voluntários" sobre a questão racial "pois são todos brancos". Não obstante, pelo menos um voluntário da ONG, nigeriano, era negro, a despeito da visível maioria de pessoas brancas ${ }^{6}$. Em outro dia, estávamos eu e o outro voluntário do PSM conversando, e ele foi buscar algo em uma sala ao lado da que estávamos. Ele apenas abriu a porta, olhou para dentro e a fechou novamente. Depois, virou-se pra mim e disse que

\footnotetext{
6 Pude testemunhar ao menos mais dois casos em que refugiados negros, um congolês e um haitiano, eram voluntários de projetos de auxílio a outros refugiados. Além dos que presenciei, pôde-se encontrar diversos outros exemplos do mesmo em pesquisas superficiais na internet.
} 
tinha um refugiado dormindo na sala, e que provavelmente ele deveria estar muito cansado. Esse "refugiado" era o voluntário nigeriano que, em podendo ser voluntário e/ou refugiado, era incluído automaticamente na segunda categoria - e apenas nela: ou porque "todos os voluntários são brancos", ou "todos os refugiados são negros".

Eu mesmo, ao conhecer uma mulher negra em uma das aulas de português e, posteriormente, encontrá-la na reunião do grupo de troca, tomei-a por refugiada. Conversando com ela após o grupo, soube que ela era cidadã estadunidense, e que tinha vindo ao Brasil passar as férias e aprender o português enquanto realizava trabalho voluntário. É possível que meu engano não tenha se dado por suas características fenotípicas: ela estava frequentando, enquanto usuária, as aulas de português e o grupo de psicoterapia de uma ONG de assistência a refugiados. Acontece que havia outros estrangeiros não refugiados frequentando esses serviços, especialmente franceses e estadunidenses: todos brancos. Nenhum deles, entretanto, me causou esse tipo de confusão.

Outros indícios da reificação do binômio "refugiado - negro" podem ser elencados: em um dos dias, presenciei uma conversa entre a coordenadora do PSM e a coordenadora das aulas de francês da ONG. Elas conversavam sobre o restaurante de um refugiado senegalês, localizado no centro de São Paulo. A coordenadora do PSM dizia que, quando esteve lá, eram servidos os cortes mais baratos da carne de boi, com gorduras e nervos, ao que a coordenadora das aulas de francês perguntou: "Mas era um restaurante de refugiados ou para refugiados?" - só posso imaginar, pois ela não se explicou alongadamente e eu achei por bem não interromper a conversa, que essa diferenciação reflita o tipo de comida servida definida pelo público frequentador, sendo o restaurante para refugiados menos criterioso em sua seleção de alimentos que o de refugiados cujo público alvo seriam brasileiros e outros estrangeiros. A coordenadora do PSM, então, respondeu que o restaurante era de um refugiado e para refugiados, dizendo que até as $13 \mathrm{~h} 30$ o público era variado, mas após esse horário eles se tornaram "os únicos brancos do lugar" - logo, todos os negros que povoaram o lugar após o horário apontado foram automaticamente classificados enquanto refugiados.

Não são só os serviços e seus agentes que acionam o racismo para descrever a experiência subjetiva do refúgio, mas também os refugiados. Se o refugiado - considerando-se nesse caso os africanos e haitianos, ainda que haitianos não sejam oficialmente considerados refugiados - só aprende que é negro no Brasil, e esse aprendizado se dá através da experimentação do racismo, é possível apontar para uma reflexividade da categoria: o racismo aponta a diferenciação em relação a alguns nacionais - os nacionais brancos, mas também entre os próprios sujeitos do refúgio. Esses sujeitos, 
então, parecem se apropriar das categorias de raça e racismo, ingerindo-as e digerindo-as, para refleti-las nos serviços de recepção, auxílio e (re)integração deles no Brasil. Em um dos grupos de troca, por exemplo, foi perguntado aos participantes se eles já haviam sofrido algum tipo de discriminação no Brasil. Um dos haitianos presentes relatou que sim, e em especial de dois tipos: racismo e injúria racial. Não por coincidência, essas - e em especial a segunda, pois racismo parece ser uma categoria de uso mais comum fora dos meios jurídicos - são as tipificações para o crime de preconceito racial previstas na legislação brasileira ${ }^{7}$. Ele relatou que, certa vez, foi a uma entrevista de emprego em um restaurante próximo à Praça da Luz, no centro de São Paulo. Lá chegando, ele conta que a dona do estabelecimento o olhou "de cima abaixo", e lhe disse que não havia vaga de emprego "para ele". Ele disse que isso se deu pelo fato de ele ser negro, e não estrangeiro, e que "há muito disso no Brasil". O fato de ele acionar as tipificações penais dos crimes de preconceito racial mostra que esses sujeitos aprendem muito sobre o racismo no Brasil, a ponto de conformar dentro das categorias jurídico-legais previstas na legislação brasileira a experiência de preconceito racial vivida.

Outro relato pode ser trazido, à guisa de exemplo, como forma de enriquecer a discussão aqui proposta. Em um evento organizado no restaurante Al-Janiah por um grupo que realiza atendimentos psicoterapêuticos e psicanalíticos na cidade de São Paulo, e cujo tema era "Imigração e moradia", um refugiado da República Democrática do Congo foi convidado a realizar uma fala. Ele encabeça um projeto de recepção e acolhimento de solicitantes de refúgio recém-chegados à cidade, fornecendo lugares para que esses sujeitos possam se instalar provisoriamente - casas e apartamentos de pessoas engajadas na questão do refúgio e que se oferecem para fornecer um pouso provisório aos recém-chegados. Sua fala foi bastante intensa do início ao fim. Primeiramente, ele contou sua história pessoal: sua família pertencia à elite congolesa, sendo seu pai engenheiro e tendo ele estudado "nos melhores colégios do Congo". Aos 19 anos, já havia comprado uma casa "e tinha sua vida estabilizada", dando aulas em uma universidade do país. Entretanto, após um tio ser assassinado, ele se sentiu impelido a investigar sua morte, e acabou sendo preso pelo regime. Seus amigos se afastaram, e ele começou a sofrer perseguição política. Um dia, sua mãe ligou para ele e disse que forças do governo haviam estado em sua casa procurando por ele. Ele conseguiu angariar US\$ 10 mil para financiar a viagem, e comprou uma passagem para o primeiro voo destinado a sair do país: era 2015, e ele veio parar no Brasil. O restante de seu dinheiro, entretanto, acabou confiscado, e ele chegou com apenas US\$20.

Injúria racial é crime previsto pelo artigo 140, parágrafo 3ํㅡ, do Código Penal brasileiro, enquanto racismo é crime previsto pela Lei 7.716/89. 
O início foi demasiadamente difícil. Com problemas em aprender a língua, sem dinheiro e sem ter onde morar, ele disse ter descoberto o racismo no Brasil: enquanto no Congo, ele era frequentemente procurado por brancos estrangeiros que desejavam ter acesso à família presidencial, no Brasil, as pessoas se levantavam de seus bancos nos ônibus para não sentar ao lado dele. Além disso, ele contou sentir uma profunda diferença na forma como refugiados "brancos" e "negros" são tratados. Tomando como exemplo a situação dos refugiados sírios, ele afirmou existir uma predileção por esses em detrimento dos refugiados negros, o que seria injustificado em sua visão: enquanto a Síria está em guerra há seis anos, o Congo está há vinte. Os refugiados negros - africanos e haitianos, na categorização construída por ele - vão morar nas ocupações ou na rua, e "não se encontra nenhum sírio nas ocupações, nem morando na rua". Para ele, refugiado é uma "categoria da ONU" que é incompleta, pois no Brasil temos "refugiados brancos e refugiados negros". Ele também discorreu sobre seu projeto de recepção e acolhimento de recém chegados, e em como as pessoas poderiam ajudar aceitando receber esses sujeitos em suas próprias casas. Ao fim de sua fala, uma representante do grupo que organizou o evento, e que tinha como incumbência comentar as falas dos palestrantes, fez observações sobre todos os temas abordados, menos sobre o racismo.

Acontecimentos bastante similares foram relatados por Zelaya (2016), que realizou pesquisa com o Grist (Grupo de Refugiados e Imigrantes Sem-Teto), em São Paulo. A autora afirma que "era bastante comum que as pessoas ressaltassem que não são todos os 'estrangeiros' os que passam por situações de desrespeito e discriminação, senão que isso acontece sobretudo com os que são 'negros'” (Zelaya, 2016, p. 414), mostrando que seus interlocutores também percebiam como desigual o tratamento dispensado a refugiados brancos e refugiados negros, e direcionando sua ação política para a problematização dessas questões junto aos serviços de ajuda humanitária, criando, assim, um "campo de interlocução em transformação" onde a posição do refugiado, enquanto vítima desprovida de voz, bem como a do Brasil, como país naturalmente acolhedor de imigrantes, são cada vez mais colocadas em cheque.

Se refugiados descobrem que são negros no Brasil, tal "descoberta" parece evocar uma temporalidade presente - se dá no hoje, no agora - e futura - a experiência política do refúgio exige que se lide e que se denuncie essa questão para uma mudança de abordagem futura por parte dos serviços de ajuda humanitária - uma ação política. Enquanto isso, o serviço de saúde mental da ONG pesquisada parece tentar apreender o sofrimento passado - o trauma -, o que pode mostrar uma tentativa de neutralização dessa experiência específica do refúgio negro. Se, por um lado, só o refugiado negro é visível uma vez que todas essas afirmações parecem ressaltar o fato de que o refugiado branco é algo diferente do refugiado negro, e a característica fenotípica parece 
ser determinante para a leitura de alguém enquanto refugiado -, por outro, só o refugiado branco aparece aos olhos dos serviços, que, ao ignorar a diferença apontada por e entre esses sujeitos e ao reificar o binômio "refugiado - negro", reforça a desigualdade de tratamento.

\section{Temporalidades do sofrimento}

Os dados apresentados remetem a uma diferenciação temporal do sofrimento entre a temporalidade dos refugiados e a do serviço de auxílio psicoterapêutico pesquisado. O trauma, enquanto categoria que descreve a experiência de sofrimento tida como inerente à condição do refúgio, remete a eventos anteriores à chegada desses sujeitos no Brasil. A própria definição da categoria de refugiado remonta à experimentação de situações de sofrimento passado que motivam o deslocamento, essencialmente forçado, por agências externas: de acordo com o ACNUR, "refugiados são pessoas que escaparam de conflitos armados ou perseguições" ${ }^{\prime \prime}$, o que os impeliria a se deslocar.

O próprio deslocamento, portanto, já estaria crivado de - e seria motivado por - experiências de sofrimento que pertenceriam a uma dimensão temporal passada: o acolhimento e auxílio desses sujeitos estaria condicionado a um sofrimento - específico, enquanto critério de elegibilidade - experimentado em seu local de partida, no que Fassin e Rechtman chamam de "traumatização da experiência", ou a "conceitualização do evento passado como uma cicatriz dolorosa" (2009, p. 22, tradução minha). O trauma, então, se estabelece como um dos modos hegemônicos de representar a relação com o passado (ibidem). O sofrimento apreendido e descrito pela categoria se dá no passado, antes da chegada ao local de acolhida, e é a própria substância da qual o refugiado é feito: a aferição dos eventos traumáticos através do trauma psicológico é critério fundamental para a construção da categoria de refugiado.

No PSM, a categoria de trauma se faz presente - muitas vezes de maneira implícita, mas tantas outras de forma explícita. Se busca, primeiramente, a apreensão desse sofrimento causado por eventos passados, anteriores à chegada desses sujeitos no Brasil. Depara-se, entretanto, com narrativas que escapam a essa tentativa: os sujeitos do tratamento, a quem não se pode perguntar abertamente sobre os traumas - e isso é expresso em uma recomendação para que não se pergunte sobre "como eles vieram parar no Brasil" -, não acionam os eventos passados para enquadrar sua experiência enquanto refugiados, a não ser quando tais eventos podem vir a justificar a evocação de uma temporalidade presente do sofrimento. O refúgio congolês, "negro", é qualitativamente diferente do refúgio sírio, "branco", por razões

\footnotetext{
8 "ACNUR explica significado de status de refugiado e migrante". Disponível em <https://
} nacoesunidas.org/acnur-explica-significado-de-status-de-refugiado-e-migrante/> . 
que evocam uma temporalidade passada - o Congo está em guerra há vinte anos, e a Síria "somente" há seis, por exemplo - para dialogar com uma temporalidade presente - a diferença entre esses dois "tipos" de refúgio se dá aqui, no Brasil - e futura - por essa razão, os serviços deveriam direcionar uma atenção diferenciada a refugiados congoleses, em específico, e a refugiados negros, em geral.

No mais das vezes, a temporalidade do sofrimento evocada pelos sujeitos do refúgio é a presente. O PSM também chega a evocar uma temporalidade presente para explicar o sofrimento derivado da experiência do refúgio: a coordenadora do Projeto, por exemplo, pontua a "falta de assistência" no Brasil como uma das causas para possíveis transtornos psíquicos, psiquiátricos ou emocionais dos refugiados. Entretanto, pasteurizar experiências particulares se mostra algo problemático para - e problematizado pelos - refugiados: nem mesmo a "falta de assistência", sofrimento presente que remete à falta de emprego, a morar nas ruas ou em ocupações clandestinas, à falta de oportunidades de estudo ou à falta de amizades no país de acolhida, atinge de maneira igual a esses sujeitos. A distribuição do sofrimento, então, obedece também a critérios raciais, ao mesmo tempo visíveis e invisíveis ao serviço de atendimento psicoterapêutico: refugiados negros sofrem e sofrerão mais pela "falta de assistência" que refugiados brancos.

Isso não significa, de forma alguma, negligenciar os sofrimentos experimentados pelos eventos ocorridos anteriormente à chegada desses sujeitos no Brasil. É importante dizer que são, sim, pessoas que experimentaram toda sorte de situações extremas - seja no passado ou no presente, e eventualmente também no futuro. Apenas aponto para como essas pessoas têm tentado - e, por vezes, parcialmente conseguido - reformular o "campo de interlocução" no qual se procura inseri-las: nenhum sujeito nega o sofrimento passado, ainda que não fale em trauma, ao passo que não é (apenas) esse o sofrimento que desejam ver mitigado pelos serviços de auxílio. Eles, então, evocam a uma temporalidade presente do sofrimento a que desejam que os serviços enderecem sua atenção: algo que está ocorrendo aqui, presente contínuo que conecta à temporalidade futura.

\section{Considerações finais}

O trabalho de pesquisa aponta para caminhos inesperados. Enquanto a expectativa inicial era abordar as problemáticas derivadas das abordagens inter e transculturais dos saberes psi; as abordagens etnopsicológicas, etnopsiquiátricas e etnopsicanalíticas; o conceito de competência cultural nos serviços médicos destinados à população imigrante e refugiada; ou mesmo a forma como novas categorias nosológicas da psiquiatria iam sendo erigidas para tratar da experiência do refúgio, como a Síndrome de Ulisses (Achótegui, 
2004; Pussetti, 2010; Ferreira, 2012), paulatinamente fui sendo apresentado a um novo cenário: o serviço da ONG pesquisada era pouco frequentado, com reuniões esparsas e pouca demanda de atendimento. Não se falava em termos de competência cultural, etnoterapias ou Síndrome de Ulisses, nem no serviço pesquisado, nem entre os refugiados ${ }^{9}$.

As abordagens "interculturais" acionadas por seus agentes - perguntar sobre como esse sujeito lidaria com aquela dificuldade específica "em sua cultura" (Formulário de pesquisa da ONG, 2016), realizar uma "escuta qualificada" sobre os problemas emocionais decorrentes do deslocamento forçado ${ }^{10} \mathrm{e}$ tentar equalizar as "diferenças culturais" através da língua, com tradução para o inglês e o francês ${ }^{11}$ - pareceram conformar um conjunto de práticas destinadas a criar o espaço humanitário ${ }^{12}$ para que o refugiado(a) traumatizado obtivesse auxílio psicoterapêutico no Brasil. O trauma enquanto a "evidência do corpo" (Fassin, Rechtman, 2009, p. 242), ou a "prova psicológica" (ibidem, p. 244) que atesta a vulnerabilidade, o sofrimento e a condição de vítima do sujeito refugiado ou do solicitante de refúgio, remetendo às causalidades que forçaram o deslocamento, quase não aparece entre esses sujeitos, e, quando efetivamente se tornou visível, foi para ser recusado enquanto termo que descreveria a experiência do refúgio.

Esse sujeito parece escapar às tentativas de conformá-lo na narrativa do trauma enquanto sofrimento passado e enquanto delimitador de sua condição de vítima. A categoria, da mesma forma que a de "refugiado", parece ser tratada enquanto bloco monolítico que homogeneíza as experiências múltiplas do refúgio (Malkki, 1995; idem, 1996) por parte do PSM, ao passo que os sujeitos do refúgio frequentemente se esforçam por coproduzir o lugar de refugiado e dos auxílios destinados a eles (Malkki, 1995; Fassin, Rechtman, 2009; Cabot, 2013; Zelaya, 2016; Pussetti, 2017), trazendo temporalidades distintas de

9 Essa, entretanto, é uma realidade multi-facetada, e outros serviços em que a inserção de campo se deu posteriormente à redação deste artigo apresentam dinâmicas diferentes das apresentadas no PSM da ONG pesquisada em 2017. Abordarei essas dinâmicas particulares sobre etnoterapias, psiquiatria cultural e serviços médico-psiquiátricos especializados em refugiados e imigrantes em trabalhos posteriores, e em minha dissertação.

${ }^{10}$ Entre os problemas listados como dificuldades emocionais decorrentes do estresse do deslocamento forçado para outros países estão "dormir mais ou menos que o normal; comer mais ou menos que o normal; menos interesse ou prazer em fazer as coisas; não ser capaz de parar ou controlar as preocupações; e pesadelos frequentes ou ansiedade exagerada". Essa lista foi recolhida do formulário de pesquisa elaborado pelo Projeto de Saúde Mental da ONG pesquisada, composto de dezessete perguntas e disponível em português, inglês e francês, para ser aplicado entre os usuários do serviço.

${ }^{11}$ Em um dos dias em que o grupo de troca foi realizado, havia ao menos três haitianas no grupo que só falavam créole. Um outro haitiano presente na reunião do grupo se ofereceu para realizar a tradução para elas, já que nenhum dos(as) voluntários(as) da ONG sabia falar aquela língua.

12 Por espaço humanitário, entendo que são os lugares, físicos ou simbólicos, onde se exerce a lógica da ajuda humanitária. 
sofrimento e exigindo uma reformulação das abordagens disponíveis ao serviço de saúde mental. O sofrimento ao qual é exigida atenção é aquele que se dá no presente e se projeta ao futuro, e se insere nas questões relativas à dificuldade de conseguir emprego, de aprender a língua e, no caso de africanos e haitianos, na "descoberta" e na experimentação do racismo brasileiro.

O próprio serviço pesquisado, ao realizar a distinção entre refugiados brancos e refugiados negros, parece fazê-lo associando o "ser negro" ao "ser refugiado", classificando automaticamente pessoas negras enquanto refugiados, e desconsiderando a existência de refugiados brancos. Ainda assim, os sujeitos do refúgio apontam para a indistinção da experiência do refúgio negro e do refúgio branco por parte dos serviços, advogando a ideia de que essa indistinção serve justamente para tratar de maneira igual àqueles que são diferentes. Uma clivagem social, política, simbólica e econômica se desenha a partir disso: tratar sírios e congoleses enquanto iguais reproduz uma desigualdade que, no caso de refugiados negros, se aprende aqui: brancos e negros não são iguais no Brasil, e a demanda pelo auxílio é, portanto, qualitativamente diferente. Só se vê o refúgio negro - "refugiados descobrem que são negros no Brasil", englobando todos os sujeitos disponíveis na categoria, e categorizando automaticamente negros frequentadores desses serviços na condição de refugiados -, mas não se vê o refúgio negro - tratar as experiências díspares do refúgio branco e do refúgio negro pasteuriza vivências desiguais, o que acarreta uma falha em fornecer o auxílio esperado pelos sujeitos do refúgio negro, uma vez que se espera tratamento particular para experiências particulares de refúgio. Por outro lado, não se vê o refúgio branco - sujeitos negros são enquadrados automaticamente na categoria de refugiado, ainda que possam ser outra coisa, enquanto sujeitos tidos como brancos, como os sírios, são automaticamente enquadrados em "outra coisa", ainda que possam ser refugiados-, mas só se vê o refúgio branco - a experiência desses refugiados com os serviços de auxílio é mais bem sucedida, evitando que eles acabem morando nas ruas, ajudando-os a conseguir emprego e, em último grau, integrando-os de maneira mais eficaz à sociedade brasileira.

A pouca procura pelo serviço de saúde mental também pode ser vista como reflexo dessa incongruência de expectativas entre o serviço e os sujeitos a quem ele se destina a auxiliar. Enquanto procura pelo trauma passado, buscando na experiência anterior à chegada no Brasil o sofrimento ao qual se deveria prestar auxílio, o serviço se vê falando sozinho, e se obriga a reformular sua abordagem a respeito da questão. As estratégias, então, se consistem em marcar os grupos de troca para os dias de aula de português - esse sim, um serviço bastante procurado - ou em reformular os temas de debate do grupo, realizando oficinas sobre empreendedorismo e dinâmicas destinadas a prepará-los para conseguir emprego - ainda que a reivindicação por parte 
dos participantes seja a de encaminhá-los para entrevistas onde só estrangeiros tomem parte -, tornando possíveis, em parte, as trocas a que o grupo se propõe. Não se trocam traumas porque os refugiados não os trazem para trocar, exigindo um outro tipo de troca que diz respeito à temporalidade presente $\mathrm{e}$ futura do sofrimento e das dificuldades vividas. Esses sujeitos não só escapam ao "campo de refugiados sem cercas", definido por Perin como os mecanismos de governo que produzem um tipo específico de sujeito apreensível para "o olho do Estado" (2014), como também se apropriam dele para transformá-lo em outra coisa a despeito das tentativas de enquadramento em categorias não compartilhadas por eles. O refúgio da loucura e do trauma passado, então, se esvazia diante do refúgio do racismo, do desemprego e da "falta de assistência", que acomete desigualmente àqueles a quem se trata enquanto iguais.

\section{Referências bibliográficas}

ACHÓTEGUI, Joseba. Emigrar en situación extrema: el síndrome del inmigrante con estrés crónico y múltiple (Síndrome de Ulisses). Revista Norte de Salud Mental, Madrid, v. 5, n. 21, p. 39-52, 2004.

ALMEIDA, Alexandra C. Gomes de. Uma reflexão sobre o trabalho de campo no contexto dos estudos imigratórios e refúgio no Brasil. Texto apresentado ao Laboratório de Estudos Migratórios da Universidade Federal de São Carlos, 2017.

BENEVIDES, Daysianne; PINTO, Antônio; CAVALCANTE, Cinthia; JORGE, Maria. Cuidados em saúde mental por meio de grupos terapêuticos de um hospital-dia: perspectivas dos trabalhadores da saúde. Interface, v. 14, n. 32, 2010.

BRANCO PEREIRA, Alexandre. "Mas é só você que vê?": A percepção social da loucura e o processo de reconstrução do universo simbólico do sujeito diagnosticado. Saarbrücken: Ed. Novas Edições Acadêmicas, 2014.

CABOT, Heath. The social aesthetics of eligibility: NGO aid and indeterminacy in the Greek asylum process. American Ethnologist, v. 40, n. 3, p. 452-466, August 2013.

DANTAS, Sylvia Duarte (org.). Diálogos interculturais: reflexões interdisciplinares e intervenções psicossociais. São Paulo: Instituto de Estudos Avançados da Universidade de São Paulo, 2012.

DEBIAGGI, Sylvia Dantas; PAIVA, Geraldo José (orgs.). Psicologia E/Imigração e Cultura. São Paulo: Ed. Casa do Psicólogo, 2004.

FASSIN, Didier. Biopolitics of otherness. Anthropology today, v. 17, n. 1, p. 3-7, 2001.

FASSIN, Didier; RECHTMAN, Richard. The empire of trauma: na inquiry into the condition of victimhood. Princeton University Press, 2009.

FERREIRA, Júlio Flávio. Negociar a cura: enquadramentos da doença em uma clínica psiquiátrica transcultural - um estudo de caso. Revista de Antropologia da UFSCar, v. 3, n. 1, p. 145-170, 2011.

FERREIRA, Júlio Flávio. Retificando a psiquiatria transcultural: Novas odisseias nas entrelinhas do Estado, da saúde e da imigração em Espanha e na União Europeia. Revista de Antropologia da UFSCar, v. 4, n. 2, p. 95-106, 2012. 
GALINA, Vivian Fadlo; SILVA, Tatiane Barbosa Bispo da; HAYDU, Marcelo; MARTIN, Denise. A saúde mental dos refugiados: um olhar sobre estudos qualitativos. Interface [online], v. 21, n. 61, p. 297-308, 2017.

HAMID, Sonia. (Des) Integrando Refugiados: Os Processos do Reassentamento de Palestinos no Brasil (Tese doutoral). Universidade de Brasília, Programa de PósGraduação em Antropologia Social, 2012.

KIRSCH, Stuart. Reverse anthropology: indigenous analysis of social and environmental relations in New Guinea. Stanford, CA: Stanford University Press, 2006.

KNOBLOCH, Felicia. Impasses no atendimento e assistência do migrante e refugiados na saúde e saúde mental. Psicologia USP, v. 26, n. 2, p. 169-174, 2015.

LATOUR, Bruno. Jamais fomos modernos: ensaios de antropologia simétrica. Rio de Janeiro: Editora 34, 1994.

LATOUR, Bruno; CALLON, Michel. Don't throw the baby out with the Bath school! A reply to Collins and Yearley. In: PICKERING, Andrew (org.). Science as practice and culture. Chicago and London: University of Chicago Press, 1992.

LOPEZ, Gabriel Angel Jimenez. Migrações humanitárias ou migrações econômicas na fronteira Brasil/Colômbia: reflexões sobre deslocados e conflitos. Tomo, Revista do Programa de Pós-Graduação em Sociologia da Universidade Federal de Sergipe, n. 26, p. 247-278, jan/jun 2015.

MEDEIROS, Gustavo C.; SAMPAIO, Daniela; SAMPAIO, Sônia; LOTUFO-NETO, Francisco. Mental health of refugees: report of a successful case in Brazil. Revista Brasileira de Psiquiatria, v. 36, n. 3, July/Sept. 2014.

MEJÍA, Rafael I. E. Desterritorialização e resistências: viajantes forçados colombianos em São Paulo e Barcelona (Tese de Doutorado). Campinas: Unicamp, 2010.

MALKKI, Liisa H. Refugees and exile: from "refugee studies" to the national order of things. Annual Review of Anthropology, v. 24, p. 495-523, 1995.

MALKKI, Liisa H. Speechless emissaries: refugees, humanitarianism and dehistoricization. Cultural Anthropology, v. 11, n. 3, p. 377-404, 1996.

NAVIA, Ângela. Exxodos e refúgios: colombianos no Sul e Sudeste do Brasil (Tese de Doutorado). Universidade Federal de Rio de Janeiro, 2014.

PEIRANO, Mariza. Etnografia não é método. Horizontes Antropológicos, v. 20, n. 42, p. 377-391, 2014.

PERIN, Vanessa. "Um campo de refugiados sem cercas": etnografia de um aparato de governo das populações refugiadas. Horizontes Antropológicos, v. 20, n. 41, p. 303-330, Jan./Junho 2014.

PUSSETTI, Chiara. Identidades em crise: imigrantes, emoções e saúde mental em Portugal. Saúde e Sociedade, v. 19, n. 1, p. 94-113, 2010.

PUSSETTI, Chiara. "O silêncio dos inocentes": os paradoxos do assistencialismo e os mártires do Mediterrâneo. Revista Interface, v. 21, n. 61, p. 263-272, 2017.

REHBERG, Katherine. Revisiting therapeutic governance: the politics of mental health and psychosocial programmes in humanitarian settings. Refugee Studies Centre, Working Paper Series no. 98. Oxford Department of International Development, University of Oxford, 2014. 
ROSA, Miriam Debieux. Migrantes, Imigrantes e Refugiados: a clínica do traumático. Revista Cultura e Extensão USP, v. 7, p. 67-76, 2012.

ROSA, Miriam Debieux; BERTA, Sandra; CARIGNATO, Taeco; ALENCAR, Sandra. A condição errante do desejo: os imigrantes, migrantes, refugiados e a prática psicanalítica clínico-política. Revista Latinoamericana de Psicopatologia Fundamental, v. 12, n. 3, Setembro 2009.

STENGERS, Isabelle. Cosmopolitcs II. University of Minessota Press, 2011.

ZELAYA, Silvia. A mobilização de refugiados e suas linguagens: notas etnográficas sobre um campo de interlocução em transformação. Cadernos de Campo, v. 25, p. 400-420, 2016.

Recebido para a publicação em 18.12.2017

Aceito para publicação em 04.06.2018

Received for publication in December 18 $8^{\text {th }}, 2017$

Accepted for publication in June $04^{\text {th }}, 2018$

ISSN impresso 1980-8585

ISSN eletrônico 2237-9843

http://dx.doi.org/10.1590/1980-85852503880005306 